\title{
An Unusual Pattern of Dyssynchronous Breathing due to Expiratory Flow Obstruction in the Scavenging System Caused by the Weight of Water Condensate
}

\author{
Kai M Chan ${ }^{1}$, Yu C Ng${ }^{2}$, Hing Y So ${ }^{3}$
}

\begin{abstract}
Background: Patient-ventilator dyssynchrony is commonly due to patient pathophysiologic factors and imprecise ventilator settings. In unusual circumstances, such dyssynchrony can also be due to faults within the equipment preventing from its normal operation during assisted mechanical ventilation.

Case description: We report a patient showing an unusual pattern of dyssynchronous breathing related to a blocked scavenging system caused by the failure of its rod valve to open. Collection of water condensate inside its reservoir bag leading to a weight drag and deformation of its shape was found to be the cause. Specifically, our patient manifested as failure to trigger with the development of high positive end-expiratory pressure (PEEP) and paradoxical pressure changes during pressure support ventilation.

Conclusion: Water condensation distal to the ventilator exhaust gas outlet may not be immediately apparent. Clinicians should remain alert with patient-ventilator dyssynchrony, especially with an unusual pattern, as it may signify equipment faults, such as expiratory gas flow obstruction within the scavenging system.

Keywords: Equipment failure, Expiratory flow obstruction, Heated humidifier, Patient-ventilator dyssynchrony, Rebreathing, Scavenging system. Indian Journal of Critical Care Medicine (2020): 10.5005/jp-journals-10071-23666
\end{abstract}

\section{BACKGROUND}

Patient-ventilator dyssynchrony occurs when the phases of breath delivered by the ventilator do not match that of the patient and it is largely attributed to patient pathophysiologic factors and the precision of ventilator settings. Common patterns of patientventilator dyssynchrony include trigger delay, inspiratory flow mismatch, short or prolong cycling, double triggering, ineffective inspiratory effort during the expiratory phase, and auto-triggering. In rare circumstances, dyssynchronous breathing can also arise when faults occur in the different parts of the breathing circuit, ventilator, or scavenging system, in particular when the types of dyssynchrony are unusual. We report a patient showing an unusual pattern of dyssynchronous breathing due to a blocked scavenging system related to the failure of its rod valve to open. Specifically, during pressure support (PS) ventilation, our patient manifested as failure to trigger with the development of high PEEP and paradoxical pressure changes in the presence of expiratory flow obstruction.

\section{Case Description}

A 44-year-old man with right vocal cord palsy and recurrent aspiration was admitted to the intensive care unit (ICU) for respiratory failure due to carbapenem-resistant Acinetobacter baumannii pneumonia. He was put on mechanical ventilator support and the ventilator (Servo-U, Maquet) was connected to a scavenging system (EVAC 180) as an additional infection control measure in face of the COVID-19 epidemic. On the fifth ICU day, the heat moisture exchange (HME) in the breathing circuit was changed to a heated humidifier (Fisher and Paykel MR850) due to copious amount of sputum. On the sixth ICU day, his condition continued to improve and he was on PS mode with PS of $10 \mathrm{cmH}_{2} \mathrm{O}$ above a PEEP of $6 \mathrm{cmH}_{2} \mathrm{O}$. Twenty-eight hours after he was put on PS mode, he

\begin{abstract}
${ }^{1,3}$ Department of Anesthesia and Intensive Care, The Chinese University of Hong Kong, Shatin, Hong Kong

${ }^{2}$ Department of ICU, Alice Ho Miu Ling Nethersole Hospital, Hong Kong Corresponding Author: Kai M Chan, Department of Anesthesia and Intensive Care, The Chinese University of Hong Kong, Shatin, Hong Kong, e-mail: chan.k.m.123@gmail.com

How to cite this article: Chan KM, Ng YC, So HY. An Unusual Pattern of Dyssynchronous Breathing due to Expiratory Flow Obstruction in the Scavenging System Caused by the Weight of Water Condensate. Indian J Crit Care Med 2020;24(11):1128-1131.
\end{abstract}

Source of support: Nil

Conflict of interest: None

became dyssynchronous with the ventilator, and labored breathing was observed. Despite the patient's respiratory effort, the backup pressure control (PC) was activated with a backup mandatory breath rate of 15 breaths/minute (bpm). Despite low inspiratory flow being delivered at a rate of $15 \mathrm{bpm}$, neither triggered nor mandatory breath could be recorded (Fig. 1A). Paradoxical changes in airway pressures were observed with a decrease in pressure from 28 to 20 $\mathrm{cmH}_{2} \mathrm{O}$ during the inspiratory phase and an increase in pressure from 20 to $28 \mathrm{cmH}_{2} \mathrm{O}$ during the expiratory phase. The ventilator wrongly regarded the expiratory pressure of $28 \mathrm{cmH}_{2} \mathrm{O}$ as peak pressure and the inspiratory pressure of $20 \mathrm{cmH}_{2} \mathrm{O}$ as PEEP. Ten to 20 seconds afterward, PS breaths were seen to be superimposed on a similar pattern of paradoxical pressure changes. Specifically, PS breaths of $10 \mathrm{cmH}_{2} \mathrm{O}$ (with airway pressure up to $17 \mathrm{cmH}_{2} \mathrm{O}$ ) were triggered by flow when the airway pressure dropped below $8 \mathrm{cmH}_{2} \mathrm{O}$ (Fig. 1B). End-tidal $\mathrm{CO}_{2}\left(\mathrm{ETCO}_{2}\right)$ varied between 75 and 90 

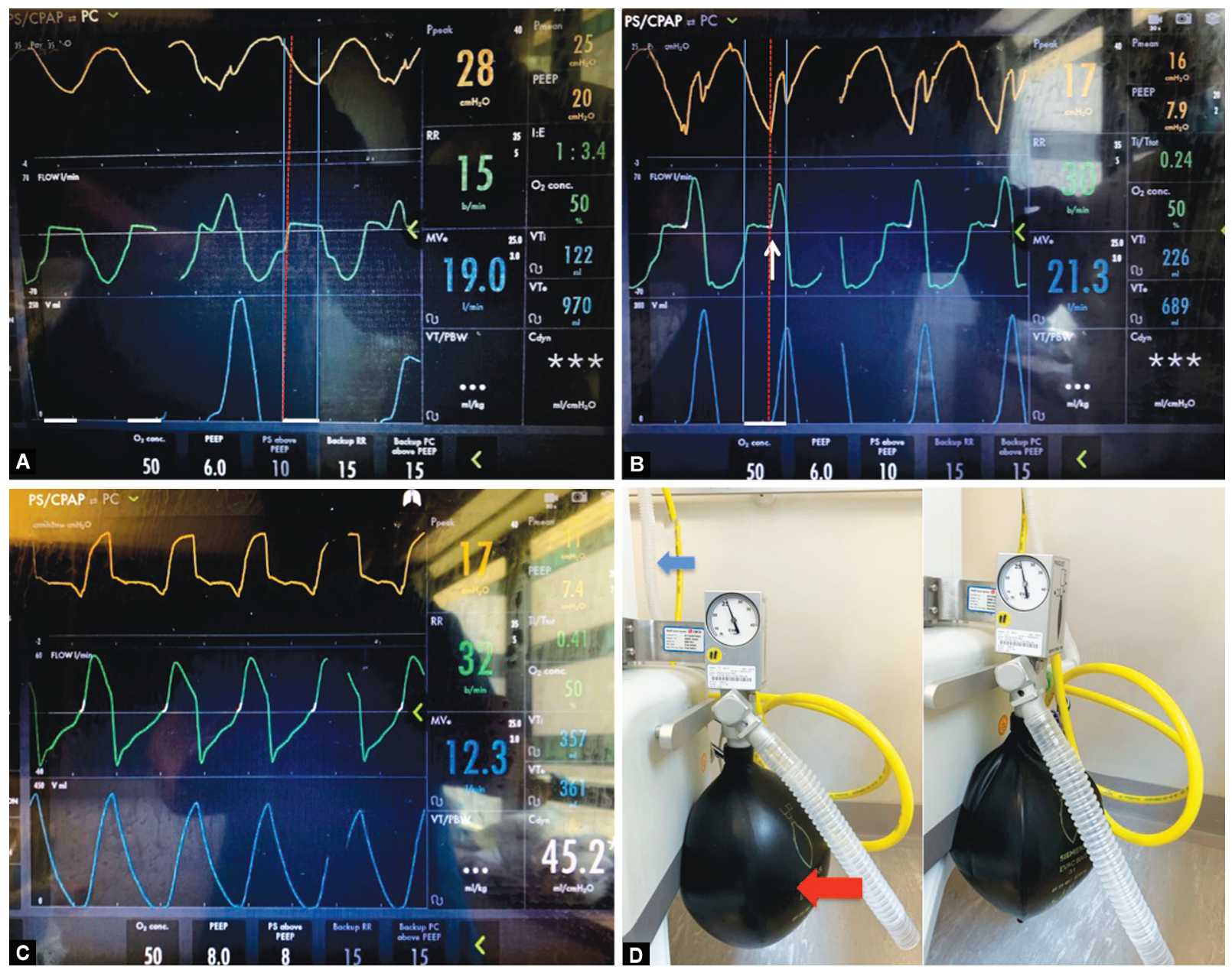

Figs 1 A to D: (A) Paradoxical airway pressure changes during inspiratory phase (white bar) and expiratory phase. PS mode was switched to back up PC as there was no triggered breath. Note the inspiratory flow of the mandatory breath started when the airway pressure drop to approximately $21 \mathrm{cmH}_{2} \mathrm{O}$ (red dash vertical line). There was no tidal volume generated by the mandatory PC breath; (B) Similar pattern of paradoxical airway pressure changes was noted. However, when the airway pressure decreases to approximately $8 \mathrm{cmH}_{2} \mathrm{O}$ (red dash vertical line), flow triggered PS breath of $10 \mathrm{cmH}_{2} \mathrm{O}$ was delivered (white arrow). The PS breath was rapidly cycled off followed by a continuation of rise in expiratory pressure; (C) Flow triggered PS breath after the water condensate in the reservoir bag of EVAC 180 was drained and refitted into the scavenging system; (D) Left: distended reservoir bag filled with water condensate (red arrow). Tubing connecting the ventilator exhaust outlet and scavenging was filled with water condensate, Right: reservoir bag partially filled with gas after the water condensate was emptied

$\mathrm{mm} \mathrm{Hg}$. It was also noted the reservoir bag of the scavenging system was hyperinflated (Fig. 1D) and water condensate was seen in the tubing connecting the ventilator exhaust outlet and the scavenging system. The reservoir bag was removed for inspection and was found filled with water condensate. Patient-ventilator dyssynchrony was abolished immediately after the water condensate was drained (Fig. 1C). Such an event did not recur when the emptied reservoir bag was reinstalled into the scavenging system (Fig. 1D).

The patient was weaned and extubated on the 8th ICU day. On the 15th ICU day, he developed right pneumothorax for which did not require drainage. He underwent further rehabilitation and was discharged from ICU after 29 days.

\section{Discussion}

EVAC 180 is a scavenging system with a valve rod mechanism. The valve is closed most of the time to protect the ventilator from the excessive negative pressure of the suction source until the reservoir bag collects enough expired gas and become distended.
The reservoir bag long axis shortened when it becomes distended and this will raise the rod, which then opens the valve to allow the evacuation of the collected gas through the suction source (Fig. 2). It is used most commonly for scavenging waste gases, such as, anesthetic gases and nitric oxide but has also been used as an infection control measure during the 2003 SARS epidemic. Of note, tubing and devices distal to the ventilator exhaust outlet are not usually heated and are prone to water condensation. This is usually not a problem when HME is used because it traps a significant portion of the moisture. However, the change to the heated humidifier in our case exacerbated water condensation by increasing the humidity of the expired gas. We postulated the reservoir bag was dragged by the weight of water condensate, thereby stretching along its length and abolishing the vertical upward movement of the rod valve even when the reservoir bag was filled. The failure of the valve to open led to obstruction to gas flow through the exhaust outlet of the ventilator and builds up back pressure in the expiratory limb. 

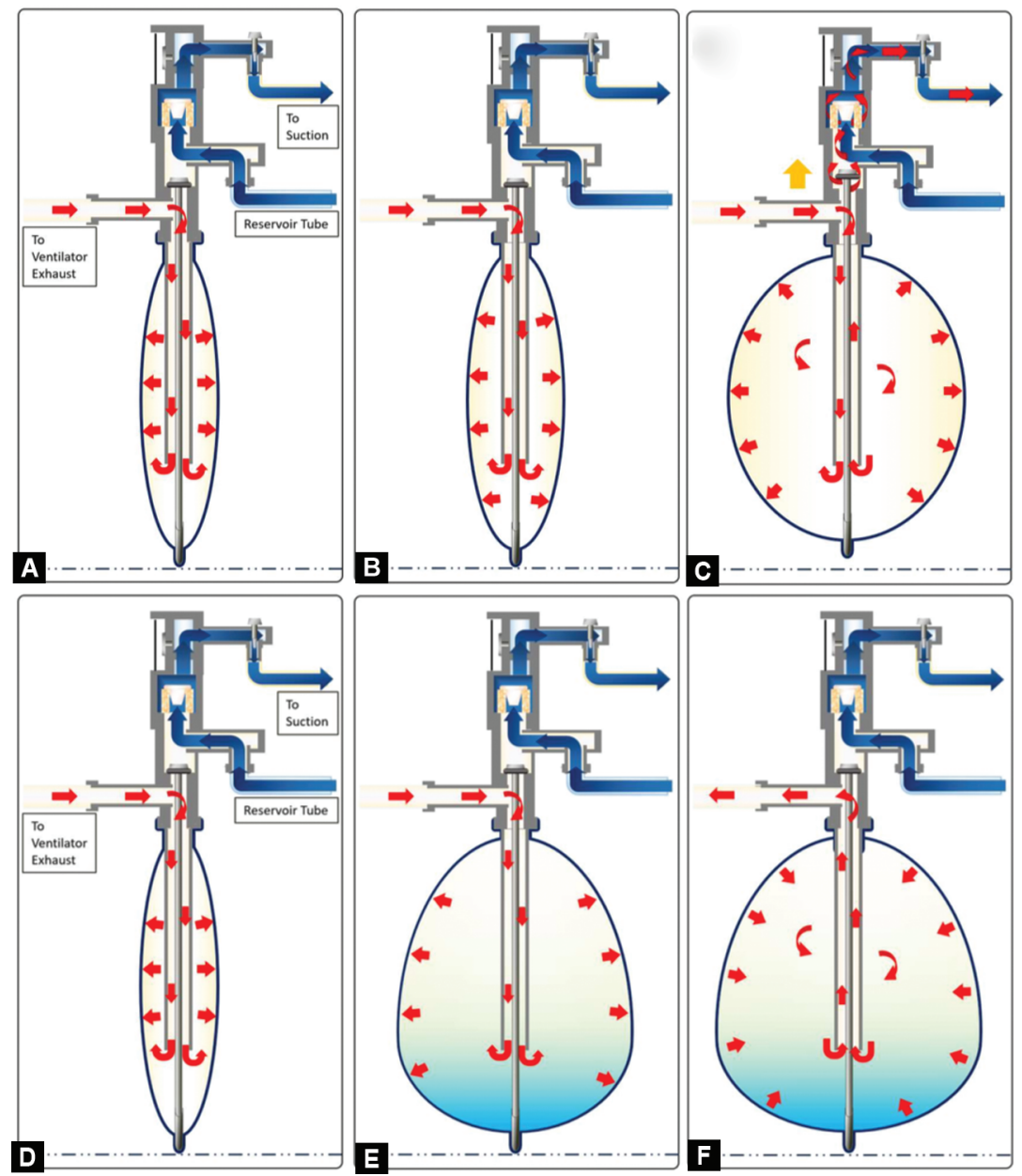

Figs 2A to F: (A and D) Exhaled gas from ventilator enters EVAC reservoir bag, the piston of the rod valve remains closed when the reservoir bag is empty. When the reservoir bag is empty, the valve closure prevents the excessive negative pressure from suction source being exerted to the ventilator. Instead, air is entrained through the reservoir tube; (B) Progressive filling of the reservoir bag from the exhaled gas from the ventilator exhaust outlet; (C) Further filling of the reservoir bag shortens the long axis of the reservoir bag. This lifts up the valve rod and the piston open, the reservoir bag is emptied again as the exhaled gas leaves the EVAC system to the suction source; (E) The water condensate collected inside the reservoir bag exerts its weight and lengthens the long axis of the reservoir bag. The rod valve remains closed despite the progressive filling by exhaled gas and reservoir bag distension. This leads to expiratory gas outlet obstruction and the paradoxical high expiratory airway pressure in our patient with forced expiratory effort; (F) The water further accumulates and drag on the reservoir bag, leading to persistent closure of the rod valve. Rebreathing occurs when the patient develops high intrinsic PEEP and fails to trigger PS breath. The ventilator delivers fresh gas flow ineffectively in the presence of high airway pressure. However, patient's spontaneous inspiratory effort leads to $\mathrm{CO}_{2}$ rebreathing

As such, the patient's forced expiration against the backpressure caused a paradoxical rise in the airway pressure during the expiratory phase and vice versa. In the presence of the high backpressure and hyperinflation of the chest, the patient could not generate the pressure drop nor the flow necessary to trigger the PS breath. Failure of triggering the PS mode resulted in activation of the backup PC mode with a PC of $21 \mathrm{cmH}_{2} \mathrm{O}$ and a mandatory rate of $15 \mathrm{bpm}$. As the set pressure of $21 \mathrm{cmH}_{2} \mathrm{O}$ was lower than the backpressure of $28 \mathrm{cmH}_{2} \mathrm{O}$, the ventilator cannot generate any effective inspiratory flow and no tidal volume could be measured. In Figure 1B, when the patient's inspiratory force was large enough to overcome the intrinsic PEEP and the airway pressure decrease to $8 \mathrm{cmH}_{2} \mathrm{O}$, PS breath of $10 \mathrm{cmH}_{2} \mathrm{O}$ was triggered by the patient's flow. However, the expiratory flow obstruction and paradoxical pressure rise persist during the expiratory phase. The $\mathrm{ETCO}_{2}$ of $75-90 \mathrm{~mm} \mathrm{Hg}$ supported the hypothesis of exhaust outlet obstruction leading to $\mathrm{CO}_{2}$ rebreathing. It was unclear whether the subsequently developed pneumothorax was related to the event or not.

External lateral dislocation of the valve rod in EVAC 180 causing expiratory gas outlet obstruction has been reported during aortocoronary bypass surgery. ${ }^{2}$ We are the first to report such gas outlet obstruction due to the weight drag of water condensate in the reservoir bag. To verify our hypothesis, we attempted to reproduce our findings by instilling water in $50 \mathrm{~mL}$ increments into the $3 \mathrm{~L}$ reservoir bag of EVAC 180 and we observed the pressure-time, flow-time, volume-time curve of the ventilator (Servo-I) connected to a test lung. Volume control (TV 500, RR 15, PEEP 6, $\mathrm{FIO}_{2}$ 0.4) was used. The peak pressure was $18 \mathrm{cmH}_{2} \mathrm{O}$ at the beginning of the test. A tidal volume of $496 \mathrm{~mL}, \mathrm{RR} 15$, and PEEP 6 $\mathrm{cmH}_{2} \mathrm{O}$ were recorded. There was no change until $700 \mathrm{~mL}$ of water had been instilled when the rod valve started to chatter without changes to ventilator pressures. The reservoir bag was moderately distended. At $800 \mathrm{~mL}$ of water instillation, the reservoir bag had 

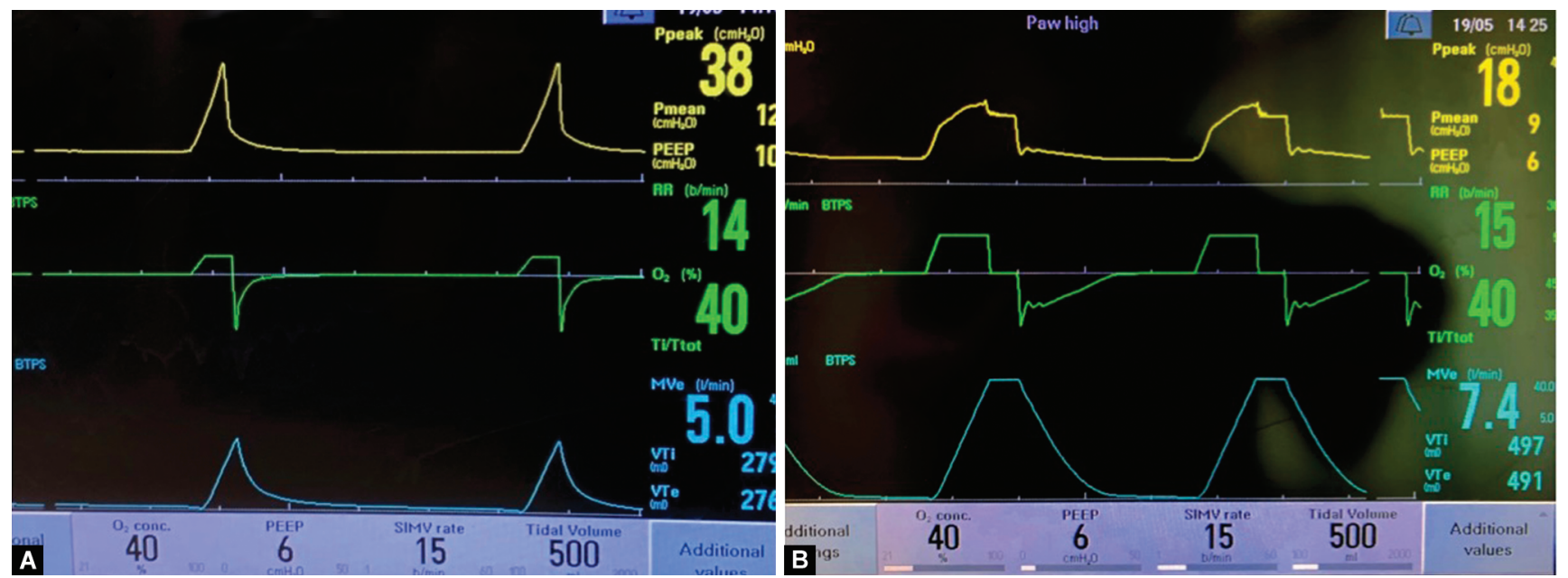

Figs $3 \mathrm{~A}$ and $\mathrm{B}$ : (A) Abrupt rise in inspiratory peak pressure up to $38 \mathrm{cmH}_{2} \mathrm{O}$ and risk in PEEP of $10 \mathrm{cmH}_{2} \mathrm{O}$ when the $3 \mathrm{~L}$ reservoir bag was filled with $800 \mathrm{~mL}$ of water. Note the set PEEP was $6 \mathrm{cmH}_{2} \mathrm{O}$; (B) Ventilator waveform returns to baseline values after the water-filled reservoir bag was removed from the scavenging system

further distension. The peak pressure rose to $38 \mathrm{cmH}_{2} \mathrm{O}$, tidal volume dropped to $279 \mathrm{~mL}$ and PEEP $10 \mathrm{cmH}_{2} \mathrm{O}$ was recorded despite the setting of $6 \mathrm{cmH}_{2} \mathrm{O}$ PEEP (Fig. 3A). A gush of air was found on the reservoir bag removal and all the ventilator parameters restored to its original values immediately (Fig. 3B). Although we did not fully replicate the condition of spontaneous ventilation, there was evidence that expiratory flow obstruction occurred when $800 \mathrm{~mL}$ of water was collected inside the 3-L reservoir bag of EVAC 180.

\section{Conclusion}

We report an unusual manifestation of dyssynchronous breathing, namely failure to trigger with high PEEP and paradoxical pressure changes, which signifies fault within the scavenging system. The shape deformation of the reservoir bag caused by the weight of water condensate was found to be the mechanism of failure of its rod valve. The simultaneous use of a heated humidifier and scavenging system was postulated to be an important risk factor.

\section{Clinical Significance}

Water condensation distal to the ventilator exhaust gas outlet may not be immediately apparent. The clinician should remain alert when an unusual pattern of patient-ventilator dyssynchrony occurs, as this may signify equipment faults, such as, expiratory gas flow obstruction within the scavenging system. We also recommend that a heated humidifier should not be used simultaneously with the EVAC 180 scavenging system, if possible. Alternatively, a moist trap in the connection tubing between the ventilator exhaust outlet and the scavenging system should be placed and frequently be inspected and changed.

\section{References}

1. Yam YC, Chen RC, Zhong NS. SARS: ventilatory and intensive care. Respirology 2003;8(s1):S31-S35. DOI: 10.1046/j.14401843.2003.00521.x.

2. Ellmauer S, Rindfleisch F, Landauer B. Acute obstruction of an anesthetic gas evacuation system. Ventilation with a Servo Ventilator 900D. Anaesthesist 1993;42(7):470-472. 